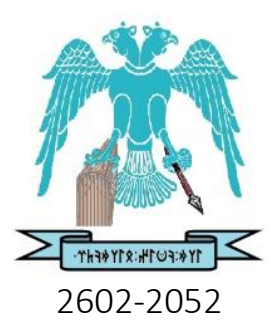

JOURNAL OF ENERGY SYSTEMS

VOLUME 3, ISSUE 3

DOI: $10.30521 /$ jes.609667

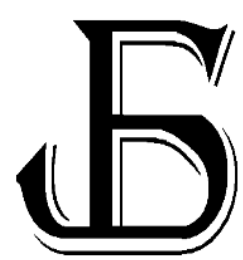

Research Article

\title{
A power circuit design for the poloidal field coils in a torus shaped plasma system
}

\author{
Bekir Dursun (D) \\ Trakya University, Edirne Technical Sciences Vocational College, Department of Electrical and Energy, \\ Edirne, Turkey, bekirdursun_@hotmail.com
}

Erol Kurt (D)

Gazi University, Technology Faculty, Department of Electrical and Electronics Engineering, Ankara, Turkey, ekurt52tr@yahoo.com

Mehmet Tekerek (D)

Kahramanmaraş Sütçüimam University, Computer Education and Instructional Technology Department, Kahramanmaraş, Turkey, tekerek@ksu.edu.tr

Arrived: 22.08.2019 Accepted: 18.09 .2019 Published: 30.09 .2019

\begin{abstract}
An initial design for a power circuit of a new plasma system is proposed and implemented in MatLab code. The plasma device is a torus and requires an excitement of wires, which are wrapped around the torus for a toroidal field and a poloidal field coil placed at the outer part of the device. This poloidal coil structure ignites an electrical field inside the chamber and that yields to a circular magnetic field inside the plasma. The proposed electrical design for this poloidal field equipment has some components including the alternating current unit and the direct current one. The circuit first uses an ac-dc converter, in order to transfer the ac grid to the dc one. Then it uses a switching scheme and a discharge circuit. The operation voltages for the poloidal field are estimated to be $1 \mathrm{kV}$, respectively. It has been proven that the designed system can produce an almost dc current with $66 \mathrm{~V}$ fluctuation, which is under the limit of $6 \%$, considering the high voltage of $1 \mathrm{kV}$.
\end{abstract}

Keywords: Poloidal field, Plasma, Converter, Ignition

Cite this paper as:

Dursun, B., Kurt, E., Tekerek, M., A power circuit design for the poloidal field coils in a torus shaped plasma system, Journal of Energy Systems, 2019, 3(3); 123-128, DOI: $10.30521 /$ jes.609667

(C) 2019Published by peer-reviewed open access scientific journal, JES at DergiPark (www.dergipark.gov.tr/jes) 


\section{INTRODUCTION}

The energy consumption of the world grows rapidly due to the industrial production and population. That causes a deficit in energy supply and only a certain proportion of this energy demand can be fulfilled by the renewable energy sector as an alternative and partially environmental-friendly character [1]. We argue as "partially friendly" because the footprint of energy is not so clean in terms of turbine, generator, photovoltaics and other equipment production. In terms of conventional fuels, many of the developing countries (with $80 \%$ usage ratio) suffer from those fuels due to environmental pollution [1]. In a most recent trend, the reaction against the climatic change arises world-widely and the international initiatives improve day by day on thermonuclear fusion energy as alternative and future energy resource [2].

In the fusion engineering applications, the power of stars are wished to be produced in the laboratory conditions via a controlled electromagnetic media. In this frame, plasmas either in RF or DC formation play an important role to produce the conditions of fusion events [3-5]. Therefore, electrical and/or magnetic confinement is vital for those plasma systems. Both generation and control of plasma are main tasks in the field of fusion. Especially, the fusion community focuses on the ideas of realization of International Thermo nuclear Experimental Reactor (i.e. ITER) project [6-7]. In what scale the plasma is generated, one of the main tasks is to design and implement an appropriate power system for the plasma unit. This paper handles some of the problems associated with the power supplies of the toroidal and poloidal coils of a new plasma system. Although our aim is not the implementation of a fusion device, the emerging of plasma structure inside the chamber is important for many applications such as medicine, material engineering, etc. In our system, since the plasma device is small, the required voltage for the poloidal field (PF) and toroidal field (TF) systems are considered as $1 \mathrm{kV}$ and $5 \mathrm{kV}$, respectively.

The designed systems have AC-DC converter topologies, which are suitable for the high voltage. Those have missions on sustaining the stability over the feeding of plasma and cutting the power, if something occurs erroneously in the electrical part. It uses a cascade voltage increase at the output terminals and those can be applied to the poloidal field coils. Thus, a new power equipment is designed in accordance with this poloidal field coils.

\section{VOLTAGE MULTIPLIER SYSTEM}

A multiple voltage multiplier system is formed by several diodes, capacitors and a source. The AC input signal is cascaded in amplitude by successive stages. Indeed, after these successive layers, a DC signal is obtained from the output of the converter. Therefore, in many literature [8-10], these are called as AC-DC converters. Historically, this kind of voltage cascades systems were invented by John Douglas Cockcroft and Ernest Thomas Sinton Walton in 1932 and called as CW type cascades [11]. At the beginning, the $\mathrm{CW}$ voltage cascades were complicated and the reliability on the DC production was low. After the improvement in semiconducting material production sector, fast diodes and high frequency capacitors were produced and applied to the $\mathrm{CW}$ type voltage cascades. In general, multiple voltage multipliers are used out of the transformers. Therefore, the topologies of the voltage cascades are determined on that whether a joint terminal of the transformer exists or not. The voltage cascades with $\mathrm{CW}$ and IT types are used in the applications with no-joint terminal transformers. The difference between the CW and IT voltage cascades is the number of layers in the sense that it is even for CW type. 
The multiple voltage cascades are the converters by using a DC voltage generated by the discharge of the capacitors attached serial to each other in a right order. Therefore, the preferences on the diodes and capacitors are important to drive the converter. For instance, in a CW type converter, a fluctuation can occur depending on the values of capacitor discharge time, which is strictly related to the charge amount and equivalent capacitance. To avoid this effect, the input frequency would be increased and the current should be decreased. Therefore, the voltage cascades are better for high frequency applications [12]. In the case of the absence of high capacity capacitor, one can make serial and parallel connections to reach the desired value for high voltage, however if the cascades are increased too much, that also causes a negative effect to get the control.

\section{PLASMA SYSTEM}

Fig. 1 shows a torus-shaped plasma cell. It has a vacuum feature under 10-5 mbar. It has an external wind system, which is responsible for the formation of toroidal electrical field inside the vessel. The outer wrapped windings over the vessel are for the poloidal electric field. The core structure denoted by a brown color provides a homogeneous field distribution at the middle of the vessel.

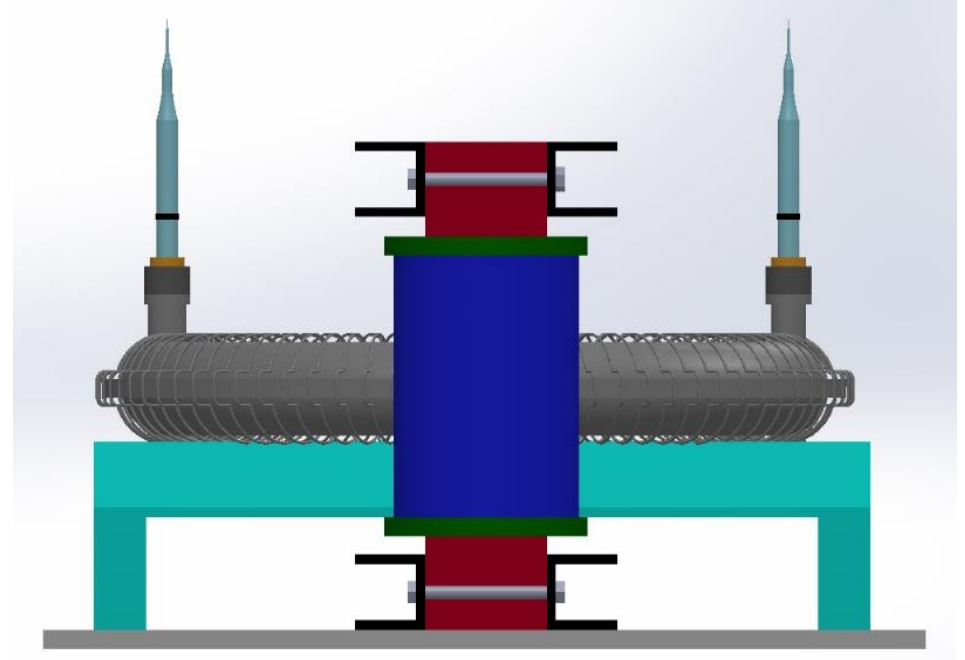

Figure 1. The plasma device with poloidal and toroidal windings and Langmuir probes.

In the poloidal field coils, the voltage cascade is composed of 5 stages to have the voltage value of $1 \mathrm{kV}$ as in Fig. 2. Table 1 gives the circuit elements to form the PF power circuit.

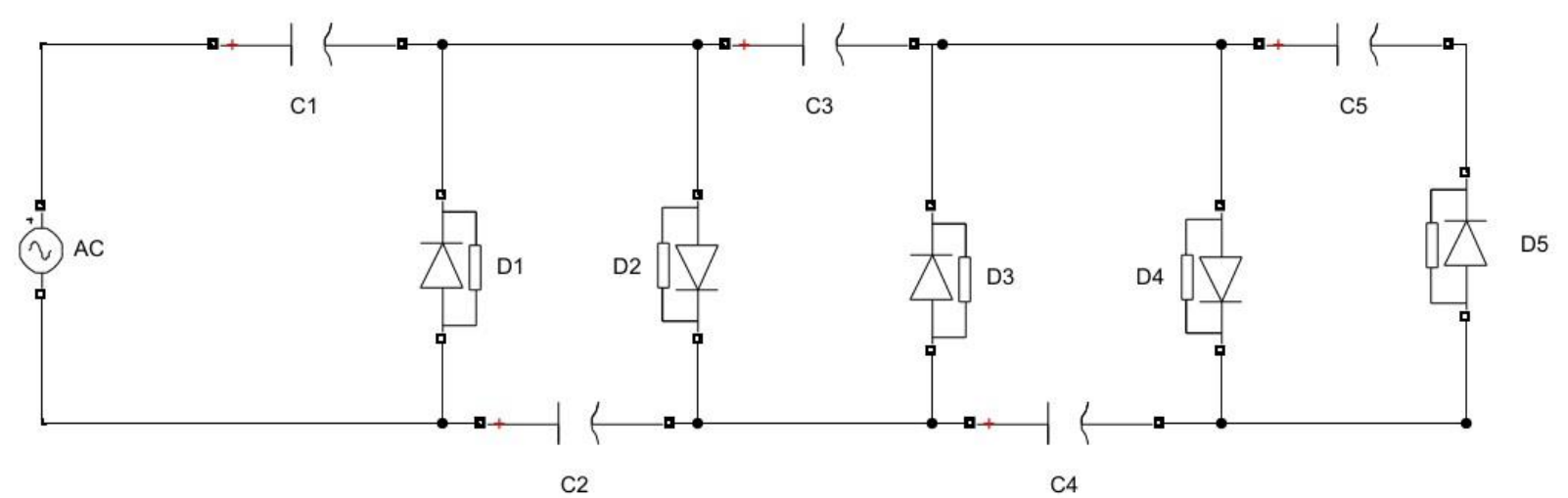

Figure 2. AC/DC Converter in PF System. 
In Fig. 3 the MatLab Simulink model is shown. Here the waveforms are obtained by measurement scopes for voltage, current and power. The values in this table gives the optimal values for the HV value.

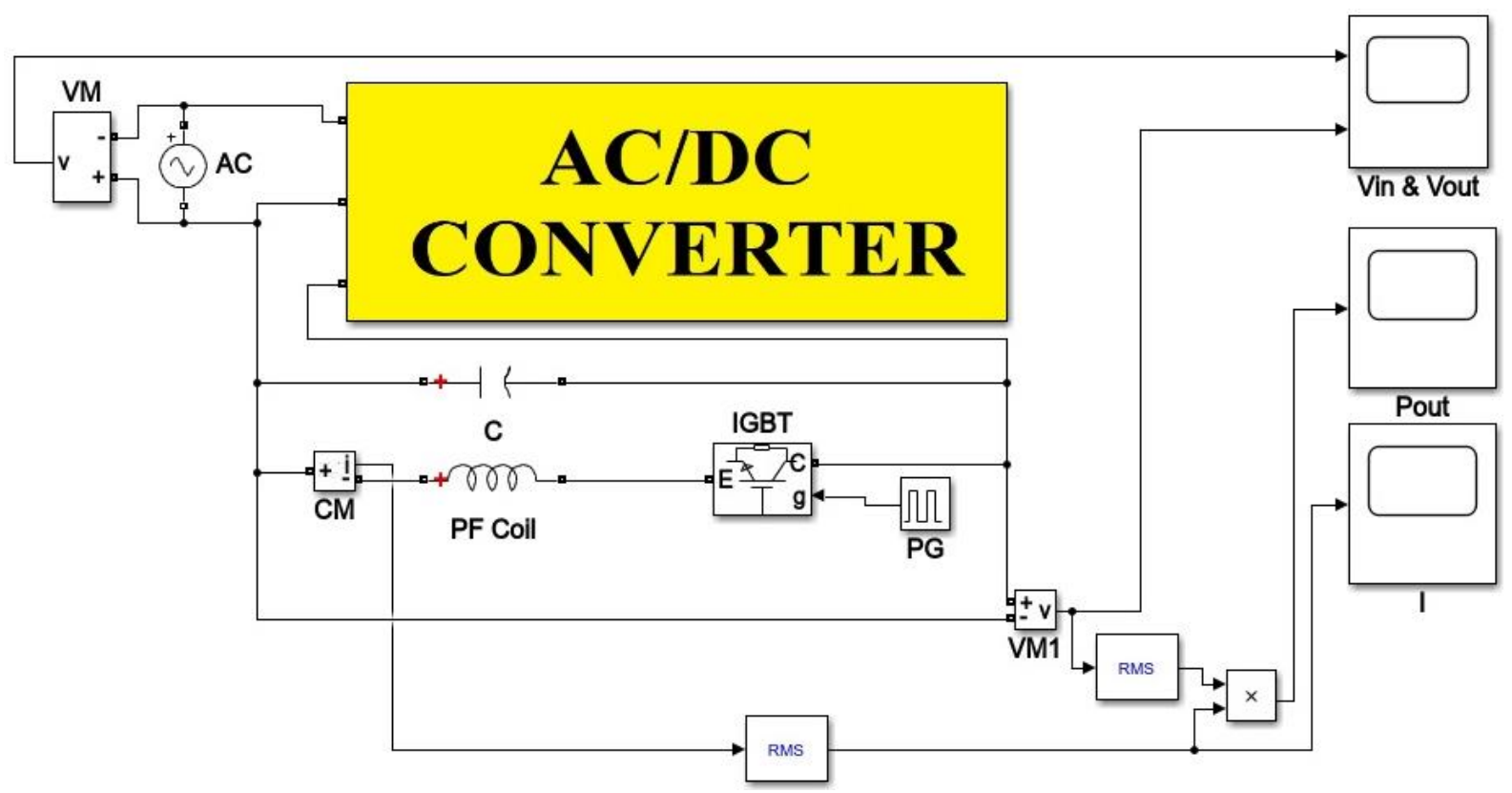

Figure 3. AC/DC Modules in PF System.

Table 1. Parameters of PF system

\begin{tabular}{ll}
\hline \multicolumn{1}{c}{ Item } & \multicolumn{1}{c}{ Specification } \\
\hline Input Voltage(AC) & $220 \mathrm{~V}$ \\
Output Voltage(DC) & $\sim 1 \mathrm{kV}$ \\
Output current & $\sim 0.82 \mathrm{~A}$ \\
Lload $_{\text {load }}$ & $462.3 \mu \mathrm{H}$ \\
$C_{n}$ & $0.137 \mu \mathrm{F}$ \\
$f_{c}$ & $100 \mu \mathrm{F}$ \\
\hline
\end{tabular}

According to circuit output, $20 \mathrm{kHz}$ frequency is found to be adequate and there is no need to decrease the frequency further. In the case of TF coils, the output current is found as $50 \mathrm{~mA}$, however it becomes $800 \mathrm{~mA}$ for PF coils.

\section{RESULTS and DISCUSSION}

Fig. 4 shows the input and output voltages of PF converter. While an $\mathrm{AC}$ waveform with a maximal value $220 \mathrm{~V}$ and $50 \mathrm{~Hz}$ is given at the input terminals, a high voltage amplitude with $1 \mathrm{kV}$ is obtained with very small fluctuation. The amplitude of the fluctuation is about $66 \mathrm{~V}$ and it is in the limit of 6.0 $\%$. 


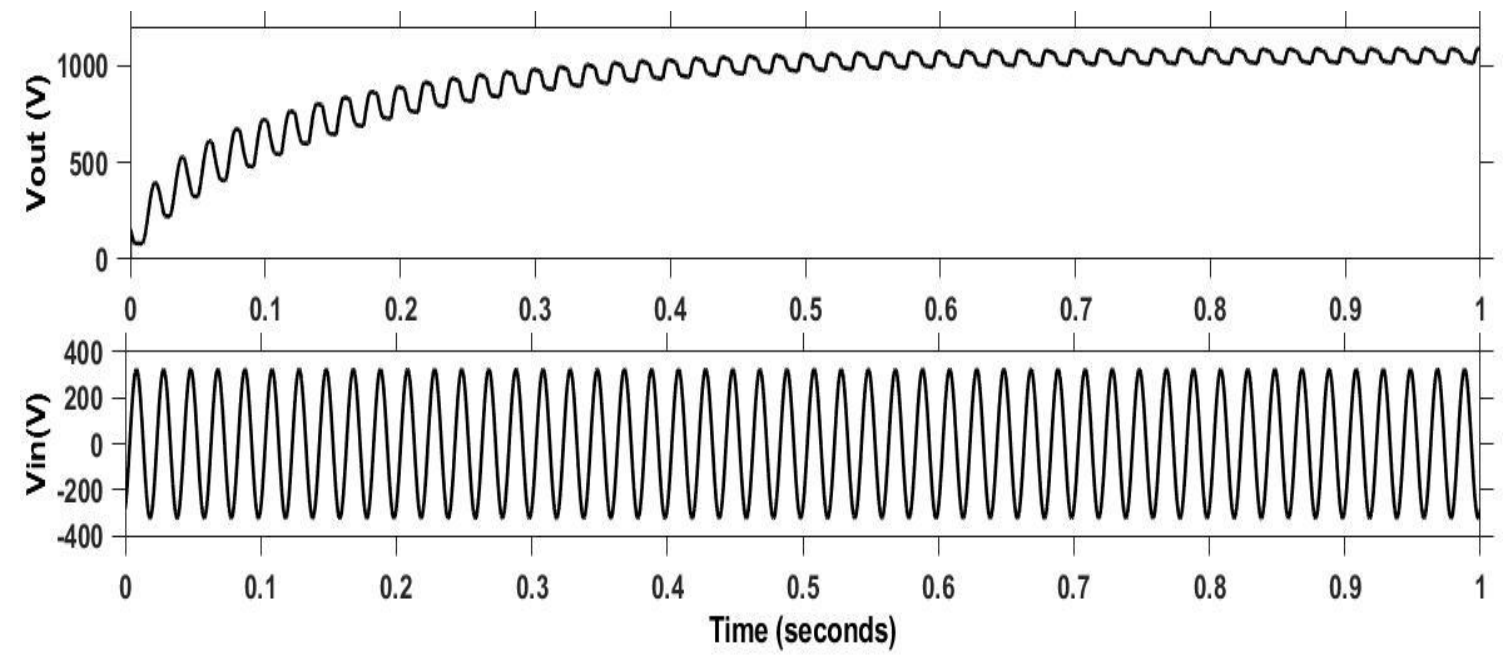

Figure 4. Input and output voltages of PF converter versus time.

Instantaneous power deviation $P$ is simulated in Fig. 5. This power gives the total gained power by the converter system including the PF coils. This plot proves that power increases up to $2 \mathrm{~kW}$ depending on the oscillation period.

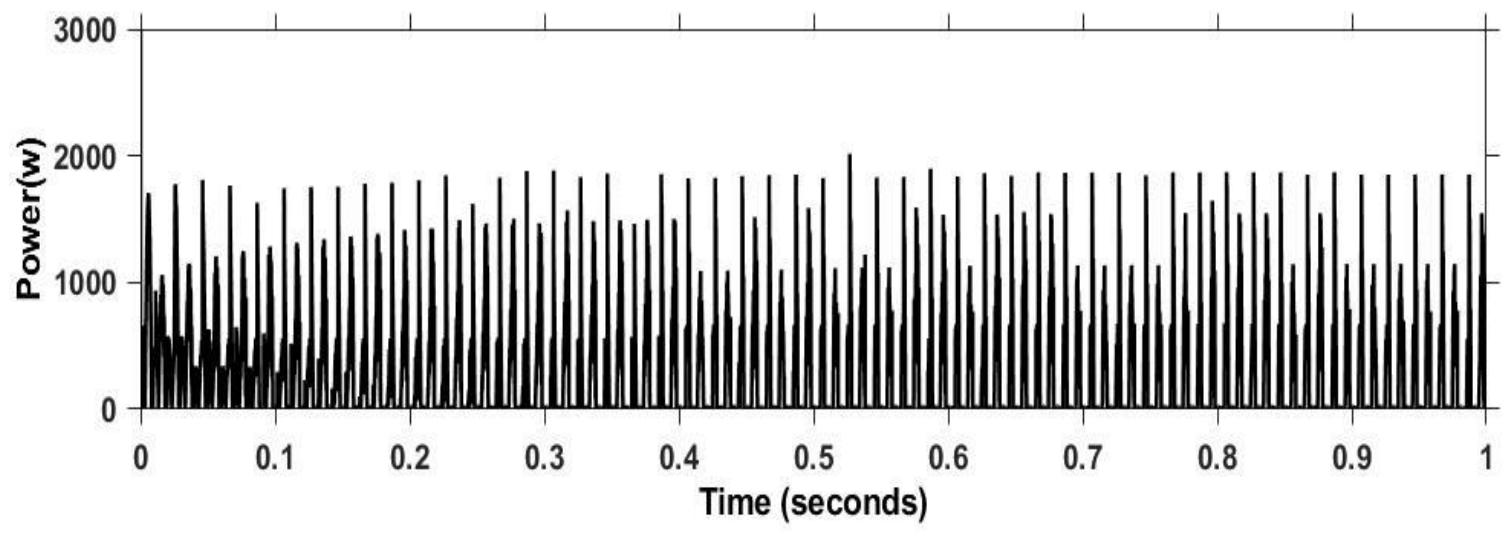

Figure 5. RMS Power deviation of PF converter.

Fig. 6 shows current over the PF coil versus time. The maximal current (i.e. $I=120 \mathrm{~A}$ ) has been obtained during a very short time of $20 \mathrm{~ms}$ after the switch is on. The current form in the inset of Fig. 6 has been reached. The current is stabilized at $0.82 \mathrm{~A}$. The current stabilization is achieved in $0.4 \mathrm{~s}$ as seen in the inset.

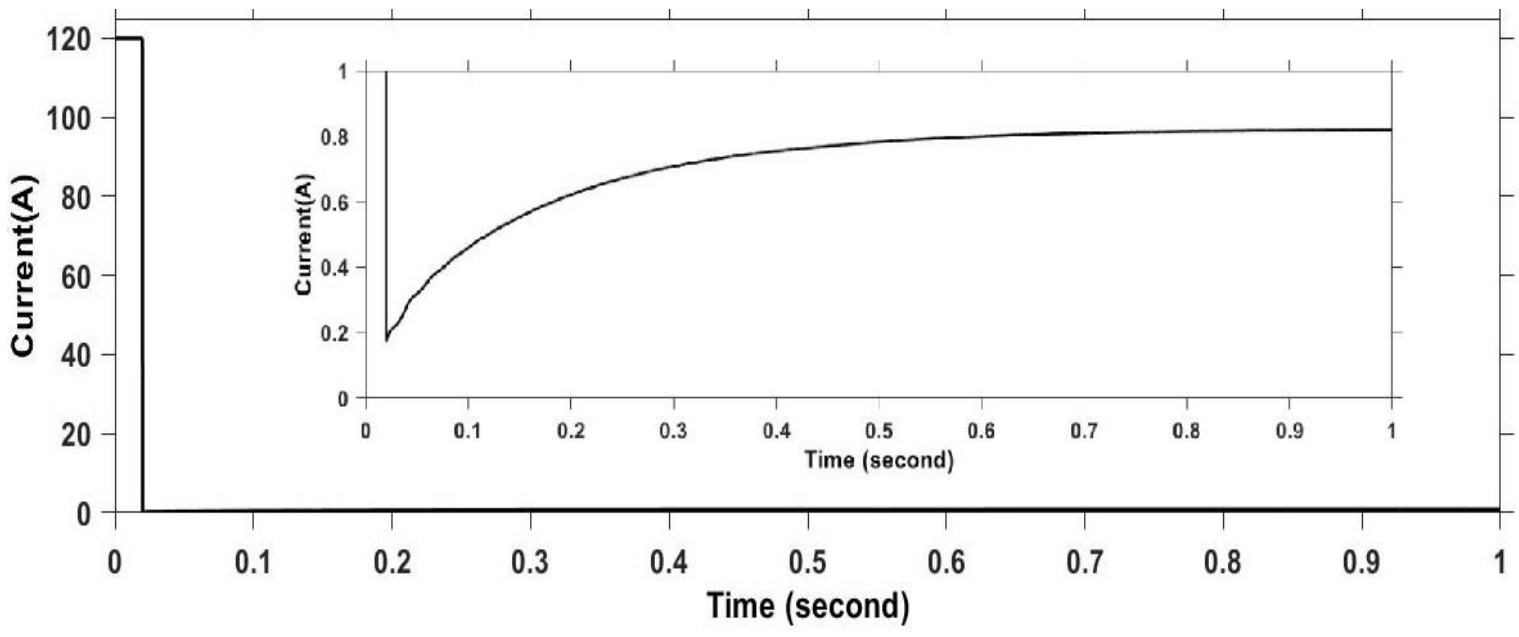

Figure 6. The output current over the PF coil just after the switch on. 


\section{CONLUSIONS}

In this study, an initial design of a new torus shaped plasma device has been performed. Besides, a voltage cascade system with 5 stages has been designed for the input power requirement of a PF coil in a plasma cell. The electrical parameters have been ascertained for the PF coils. It has been proven that the designed system can produce almost a dc current with $66 \mathrm{~V}$ of fluctuation, which is under the limit of $6.0 \%$, considering the high voltage of $1 \mathrm{kV}$. The resulting current value has been estimated as 0.82 A, which is sufficient for a low-pressure plasma device.

\section{REFERENCES}

[1] Bizon N, Lopez-Guede JM, Kurt E, Thounthong P, Mazare AG, Ionescu LM, Iana G., Hydrogen economy of the fuel cell hybrid power system optimized by air flow control to mitigate the effect of the uncertainty about available renewable power and load dynamics. Energy Conversion and Management, 2019, 179, 152-165.

[2] Srilatha B, Sinha AK., Design of pulsed power system for fusion reactor, International Conference on Power Systems, Kharagpur, 2009, 1-6. DOI: 10.1109/ICPWS.2009.5442709

[3] Akgün Y, Bölükdemir AS, Kurt E, Öncü T, Alaçakir, A., Preliminary plasma focus studies at ODAK-3K device using track detectors. Plasma Devices Operations, 2009, 17(4), 293-300.

[4] Hora H, Miley GH, Ghoranneviss M, Malekynia B, Azizi N, He XT., Fusion energy without radioactivity: laser ignition of solid hydrogen-boron (11) fuel. Energy \& Environmental Science, 2010, 3(4), 478-485.

[5] Benfattol I, Mondinol PL, Roshall A, Coletti A, Hrabal D, Maschio A, Piovan R, Tencod S, Bulgakov S, Kuchinski V., AC/DC Converters for the ITER Poloidal Field System. Proceedings of $16^{\text {th }}$ International Symposium on Fusion Engineering. Champaign, IL, USA, 1995, 1, 658-661 DOI: 10.1109/fusion.1995.534310.

[6] Mondino PL. The ITER tokamak and its power supply, Proceedings of the International Power Electronics Conference, Yokohama, 1995, 869-874.

[7] Yue, L., Lee, I., and Yao, X., Tokamak vertical stability coil power supply based on modular multilevel converter, IEEE International Power Modulator and High Voltage Conference (IPMHVC), San Francisco, CA, 2016, 447-452. DOI: 10.1109/IPMHVC.2016.8012870

[8] Kiguchi, R., and Nishida, Y., Boost DC-DC Converter Cascade System for High Boost-Rate Application, International Conference on Smart Grid (icSmartGrid), Nagasaki, Japan, 2018, 283-286. DOI: 10.1109/ISGWCP.2018.8634483

[9] Isobea T, Takakua T, Munakataa T, Tsutsuia H, Tsuji-Iioa S, Matsukawab T, Shimadaa R., Fusion Power Supplies using Magnetic Energy Recovery Switch, $21^{\text {st }}$ IEEE/NPS Symposium on Fusion Engineering SOFE 05, Knoxville, TN, 2005, 1-4. DOI: 10.1109/FUSION.2005.252988

[10] Chikaraishi, H., Extra-low-voltage DC power supply for superconducting coil using piezoelectric-actuatordriven mechanical contact, $19^{\text {th }}$ European Conference on Power Electronics and Applications (EPE'17 ECCE Europe), Warsaw, 2017, 1-8. DOI: 10.23919/EPE17ECCEEurope.2017.8098947

[11] Cockcroft John Douglas, Walton E. T. S. and Rutherford Ernest Experiments with high velocity positive ions.-(I) Further developments in the method of obtaining high velocity positive ions, Proc. R. Soc. Lond. A, 1932, 136(830), 619. DOI: 10.1098/rspa.1932.0107

[12] Öndin U., Design of high frequency high voltage DC-DC converter (Unpublished Master Thesis). Institute of Natural and Applied Sciences, Gebze Technical University, 2009, Turkey. 